\title{
Association of microalbuminuria with metabolic syndrome: a cross-sectional study in Bangladesh
}

Muntakim Mahmud Saadi ${ }^{1}$, Manindra Nath Roy ${ }^{2}$, Rubena Haque ${ }^{2}$, Farida Akhter Tania ${ }^{3}$, Shakil Mahmood ${ }^{4}$ and Nurshad $\mathrm{Ali}^{5^{*}}$ (i)

\begin{abstract}
Background and aims: The objectives of this study were to estimate the prevalence of microalbuminuria and examine the association of microalbuminuria with metabolic syndrome (MetS) and its component in a Bangladeshi adult cohort.

Methods: This cross-sectional study included 175 subjects (84 males and 91 females; aged 19-59years), recruited from the outdoor Department of Medicine and Endocrinology of a medical college hospital in Dhaka, Bangladesh. Lipid profile and fasting blood glucose (FBG) were measured in serum and albumin and creatinine were determined in urine samples. Microalbuminuria was defined as the urinary albumin-to-creatinine ratio (ACR) of 30 to $300 \mathrm{mg} / \mathrm{g}$. The MetS was defined according to the criteria of the National Cholesterol Education Program (NECP). The association of microalbuminuria with MetS and its components was evaluated by multivariate logistic regression analysis.

Results: Among the study subjects, $66.3 \%$ were hypertensive and $70.3 \%$ were diabetic individuals. Overall, the prevalence of microalbuminuria was $29.7 \%$ with $31 \%$ in males and $28.6 \%$ in females. Microalbuminuria was 2.6 fold higher in hypertensive and diabetic adults than in the non-hypertensive or non-diabetic adults. The prevalence of microalbuminuria was much more frequent in persons with the MetS (36.0\%) than the persons without the MetS (5.4\%). The levels of FBG, systolic blood pressure (SBP), diastolic blood pressure (DBP) and triglycerides were significantly higher ( $p<0.01$ for all cases) in subjects with microalbuminuria. In regression analysis, after adjusting for sex, age, and body mass index, microalbuminuria was strongly correlated with MetS followed by elevated BP and FBG ( $p<0.01$ for all cases).

Conclusions: Microalbuminuria was strongly associated with MetS in Bangladeshi adults. Elevated BP and FBG were the most predominant components of MetS among the study subjects. Comprehensive management of MetS at its early stage can be effective to prevent and reduce the progression of kidney injury and cardiovascular complications.
\end{abstract}

Keywords: Microalbuminuria, Metabolic syndrome, Prevalence, Bangladeshi adults

\footnotetext{
* Correspondence: nur_rubd@yahoo.com; nali-bmb@sust.edu

${ }^{5}$ Department of Biochemistry and Molecular Biology, Shahjalal University of Science and Technology, Sylhet 3114, Bangladesh

Full list of author information is available at the end of the article
}

(c) The Author(s). 2020 Open Access This article is licensed under a Creative Commons Attribution 4.0 International License, which permits use, sharing, adaptation, distribution and reproduction in any medium or format, as long as you give appropriate credit to the original author(s) and the source, provide a link to the Creative Commons licence, and indicate if changes were made. The images or other third party material in this article are included in the article's Creative Commons licence, unless indicated otherwise in a credit line to the material. If material is not included in the article's Creative Commons licence and your intended use is not permitted by statutory regulation or exceeds the permitted use, you will need to obtain permission directly from the copyright holder. To view a copy of this licence, visit http://creativecommons.org/licenses/by/4.0/. The Creative Commons Public Domain Dedication waiver (http://creativecommons.org/publicdomain/zero/1.0/) applies to the data made available in this article, unless otherwise stated in a credit line to the data. 


\section{Background}

Microalbuminuria is considered as an early indicator of chronic renal disorder, vascular dysfunction and cardiovascular mortality [1-3]. Microalbuminuria is more frequent in subjects with type 2 diabetes [3] and has been included in the unifying definition of metabolic syndrome (MetS) suggested by the WHO [4]. In previous studies, microalbuminuria was associated with hypertension and abdominal obesity $[5,6]$. However, the inclusion of microalbuminuria as an essential component of the MetS remains controversial.

MetS is a group of metabolic abnormalities characterized by elevated blood pressure, hyperglycemia, abdominal obesity, high triglycerides, and reduced high-density lipoprotein cholesterol that collectively increases the risk of diabetes, cardiovascular diseases, and overall mortality [7-9]. The American Heart Association criteria [10] and the Adult Treatment Panel III criteria (ATP III) [11] did not include microalbuminuria as part of MetS. Nonetheless, several studies showed an association of microalbuminuria with MetS and its components in adults [1216]. For example, in the third National Health Nutritional Examination Survey in the US, microalbuminuria showed an association with the components of MetS; blood pressure and fasting blood glucose [16]. In another study, a positive association has been reported for microalbuminuria with elevated blood pressure, high TG and reduced HDL-C [17].

In the recent years, the prevalence of MetS is rapidly increasing both in developing and developed nations. In Bangladesh, the prevalence of MetS has been increased over the last few decades. A review by Chowdhury et al. [18] reported a high prevalence of MetS (30\%) in the Bangladeshi population. A very recent study showed the prevalence of MetS 22\% in general adults with $21.9 \%$ in males and $22.1 \%$ in females [19]. A few studies conducted in Eastern Asia showed a relationship between microalbuminuria and MetS but generated inconsistent results with the components of MetS [12-15]. Therefore, it is important to examine whether microalbuminuria is associated with MetS in general adults. Given the rising prevalence of MetS in Bangladeshi adults, this crosssectional study was conducted to examine the relationship of microalbuminuria with MetS and its components in a Bagladeshi adult cohort.

\section{Methods}

\section{Study population}

This cross-sectional study was conducted at the Department of Biochemistry of Sir Salimullah Medical College, Dhaka, Bangladesh. The study participants $(n=175)$ were enrolled from the outdoor Department of Medicine and Endocrinology of Mitford Hospital, Dhaka, Bangladesh from March 2017 to January 2018. The participants underwent the Department for their physical checkup and treatment. The preliminary inclusion criteria were both genders, aged $\geq 18$ years, free from chronic diseases such as stroke, arthritis and cancer. However, lactating mothers, pregnant women, and subjects with a history of alcohol consumption, hepatotoxic drug intake, and self-reported indications of acute or chronic hepatitis B infection were excluded from the study. This study was approved by the institutional Ethics Committee of Sir Salimullah Medical College and Hospital, Dhaka, Bangladesh. All study participants were informed about the study aims and we obtained written informed consent from them before inclusion in the study. We followed the institutional guidelines and regulations to perform all steps of the methodology section.

\section{General data collection}

Individual anthropometric data eg. age, gender, height, weight and information on lifestyle factors were included in a short questionnaire form maintaining the standard measure described elsewhere [20-23]. Briefly, body weight was measured to the nearest $0.10 \mathrm{~kg}$ by a digital weighing machine (Beurer 700, Germany) and body height was measured to the nearest $0.10 \mathrm{~cm}$ by height measuring tape wearing light clothes and no shoes. The body mass index (BMI) was calculated as body weight in killograms divided by height in meters squared [19]. Waist circumference (WC) was measured using a general tape that was placed midway between the lowest border of the ribs and iliac crest. Systolic blood pressure (SBP) and diastolic blood pressure (DBP) were measured by an automated sphygmomanometer (Omron M10, Omron Corporation, Tokyo, Japan) and the average value was used in the calculation [24-26]. The accuracy of the obtained data was confirmed by repeated-measures analysis.

Blood and urine sample collection and laboratory analysis The venous blood samples were obtained after 10-12 $\mathrm{h}$ overnight fasting from the participants [19]. Then the samples were centrifuged at $3000 \mathrm{rpm}$ for $15 \mathrm{~min}$ and isolated serum was stored at $-20^{\circ} \mathrm{C}$ until analysis. Fasting blood glucose (FBG), triglycerides (TG), total cholesterol (TC), low-density lipoprotein cholesterol (LDL-C) and high-density lipoprotein cholesterol (HDL-C), were measured by standard colorimetric methods. Fasting firstmorning void urine samples were collected for the determination of urinary creatinine and albumin concentrations. Urinary creatinine was measured using a kinetic assay applying Jaffe creatinine method and urinary albumin was measured using an immunoturbidimetric method. Urine albumin-creatinine ratios (ACR) were calculated for all subjects. These measurements accuracy were maintained through the standard calibration regularly. 


\section{Diagnostic criteria}

MetS was diagnosed based on the criteria of the National Cholesterol Education Program - Adult Treatment Panel III (NCEP-ATP III) [27]. The variables of MetS were defined as follows: i) Elevated blood pressure ( $\mathrm{SBP} \geq 130 \mathrm{mmHg}$ and/or DBP $\geq 85 \mathrm{mmHg}$ or antihypertensive medication intake); ii) raised waist circumference ( $>102 \mathrm{~cm}$ for men and $>88 \mathrm{~cm}$ for women); iii) hypertriglyceridemia (TG $\geq 150 \mathrm{mg} / \mathrm{dL}$ ); iv) hyperglycemia (FBG $\geq 100 \mathrm{mg} / \mathrm{dL})$ and $\mathrm{v})$ low HDL-C $(<40 \mathrm{mg} / \mathrm{dL}$ for men and $<50 \mathrm{mg} / \mathrm{dl}$ for women) [19]. MetS was identified among the participants who had at least three of the above components. SBP $\geq 140 \mathrm{mmHg}$ and/or $\mathrm{DBP} \geq 90$ $\mathrm{mmHg}$ were considered to define hypertension [28]. The presence of diabetes was confirmed by the American Diabetes Association criteria as the fasting blood plasma glucose level of $\geq 126 \mathrm{mg} / \mathrm{dL}$ or random plasma glucose $\geq 200 \mathrm{mg} / \mathrm{dL}$ [29], or self-reported recent use of hypoglycemic medication. Microalbuminuria was defined as a urinary albumin-to-creatinine ratio (ACR) of 30 to $300 \mathrm{mg} / \mathrm{g}$ [16].

\section{Statistical analysis}

Statistical data analyses were done using IBM SPSS version 23. Data are presented as mean $\pm \mathrm{SD}$. Categorical variables were analyzed using the Chi-square test. Comparison of the baseline data in the male-female group was done by the independent sample t-test. The relationship between microalbuminuria and levels of baseline variables was determined by Pearson's correlation coefficient test. Multivariate logistic regression analysis was performed to evaluate the association of microalbuminuria with MetS and its components, after controlling covariates, including sex, age, and BMI. In regression analysis, MetS components were mutually adjusted. $P$-values of $<0.05$ were considered as statistically significant.

\section{Results}

The baseline characteristics of the study participants are presented in Table 1. In total, 175 participants (84 males and 91 females) were enrolled in the present study. Males, compared to females, were slightly older. No significant difference was observed for age, BMI, blood pressure, FBG, urinary creatinine and albumin and lipids except HDL-C $(p<0.05)$ between males and females. The prevalence of hypertension and diabetes was 66.3 and $70.3 \%$, respectively among participants. Overall, microalbuminuria was present in $29.7 \%$ of subjects with $31 \%$ in males and $28.6 \%$ in females. The prevalence of microalbuminuria was $41.4 \%$ in hypertensive and $35.8 \%$ diabetic individuals, and $13.6 \%$ in non-diabetic and nonhypertensive individuals. The overall prevalence of MetS

Table 1 Anthropometric and metabolic characteristics of the study subjects

\begin{tabular}{|c|c|c|c|c|}
\hline Characteristics & Total & Male & Female & $P$-value \\
\hline $\mathrm{N}$ & 175 & 84 & 91 & - \\
\hline Age (years) & $42.6 \pm 8.1$ & $43.3 \pm 8.2$ & $41.9 \pm 8.0$ & 0.293 \\
\hline $\mathrm{BMI}\left(\mathrm{kg} / \mathrm{m}^{2}\right)$ & $27.3 \pm 3.4$ & $26.8 \pm 3.3$ & $27.8 \pm 3.5$ & 0.055 \\
\hline WC (cm) & $93.9 \pm 7.1$ & $94.3 \pm 6.9$ & $93.7 \pm 7.4$ & 0.592 \\
\hline $\mathrm{SBP}(\mathrm{mm} \mathrm{Hg})$ & $136.7 \pm 22.1$ & $138.3 \pm 20.5$ & $135.2 \pm 23.5$ & 0.354 \\
\hline $\mathrm{DBP}(\mathrm{mm} \mathrm{Hg})$ & $88.4 \pm 10.0$ & $89.4 \pm 8.7$ & $87.5 \pm 11.1$ & 0.203 \\
\hline $\mathrm{FBG}(\mathrm{mg} / \mathrm{dL})$ & $169.0 \pm 59.0$ & $163.7 \pm 62.1$ & $173.9 \pm 55.8$ & 0.255 \\
\hline $\mathrm{TC}(\mathrm{mg} / \mathrm{dl})$ & $216.1 \pm 43.8$ & $210.7 \pm 40.5$ & $221.1 \pm 46.3$ & 0.117 \\
\hline $\mathrm{TG}(\mathrm{mg} / \mathrm{dL})$ & $198.3 \pm 79.7$ & $195.6 \pm 66.2$ & $200.7 \pm 90.7$ & 0.677 \\
\hline $\mathrm{HDL}-\mathrm{C}(\mathrm{mg} / \mathrm{dL})$ & $37.3 \pm 5.8$ & $36.3 \pm 4.8$ & $38.2 \pm 6.4$ & 0.034 \\
\hline LDL-C (mg/dL) & $140.1 \pm 41.4$ & $136.5 \pm 40.0$ & $143.4 \pm 42.5$ & 0.275 \\
\hline UA (mg/L) & $45.2 \pm 54.6$ & $45.6 \pm 54.0$ & $44.9 \pm 55.5$ & 0.927 \\
\hline UCR (mg/dL) & $181.6 \pm 92.0$ & $183.9 \pm 91.1$ & $179.4 \pm 93.2$ & 0.745 \\
\hline $\mathrm{ACR}(\mathrm{mg} / \mathrm{g} \mathrm{Cr})$ & $26.6 \pm 36.9$ & $24.7 \pm 34.7$ & $28.3 \pm 38.9$ & 0.526 \\
\hline Hypertension, n (\%) & $116(66.3)$ & $59(70.2)$ & $57(62.6)$ & $<0.05$ \\
\hline Diabetes, n (\%) & $123(70.3)$ & $53(63.1)$ & $70(76.9)$ & $<0.05$ \\
\hline Microalbuminuria, n (\%) & $52(29.7)$ & $26(31.0)$ & $26(28.6)$ & $<0.05$ \\
\hline MetS, n (\%) & $142(81.1)$ & $67(79.8)$ & $75(82.4)$ & $<0.05$ \\
\hline
\end{tabular}

$B M I$ body mass index, WC waist circumference, SBP systolic blood pressure, DBP diastolic blood pressure, FBG fasting blood glucose, $T C$ total cholesterol, $T G$ triglyceride, $H D L-C$ high-density lipoprotein cholesterol, $L D L-C$ low-density lipoprotein cholesterol, UA urinary albumin, UCR urinary creatinine, $A C R$ urinary albumin to creatinine ratio, MetS metabolic syndrome. Data are presented as mean \pm SD. $P$-values are obtained from Independent sample t-test in comparison between male-female groups. Chi-Square test was applied to determine $p$-values for categorical variables 
was slightly higher in females $(82.4 \%)$ than in the male (79.8\%) participants.

Table 2 shows the anthropometric characteristics and prevalence of each component of the MetS by microalbuminuria status. The levels of FBG, blood pressure and TG were significantly higher $(p<0.01$ for all cases) in participants with microalbuminuria. Microalbuminuria was much more prevalent in persons with the MetS (36.0\%) than persons without the MetS (5.4\%) (Fig. 1). The prevalence of microalbuminuria was higher in males with the MetS. The relationship between the individual component of MetS and ACR are presented in Fig. 2. A positive and significant association was observed for ACR with SBP $(p<0.001)$, DBP $(p<0.01)$, FBG $(p<0.01)$ and serum TG $(p<0.05)$ levels. After adjustment of age, sex and BMI in logistic regression analysis, microalbuminuria was significantly associated with elevated BP and high FBG $(p<0.01$ for both cases) (Table 3$)$. With a similar adjustment of covariates in the regression model, microalbuminuria was strongly associated with the MetS (OR 4.38, $p<0.01$ ).

\section{Discussion}

In the present study, we found a strong positive association between microalbuminuria and MetS among the study subjects. Microalbuminuria was common among

Table 2 Anthropometric and metabolic characteristics according to albuminuria status

\begin{tabular}{|c|c|c|c|}
\hline Characteristics & $\begin{array}{l}\text { Normoalbuminuria } \\
(<30 \mathrm{mg} / \mathrm{g})\end{array}$ & $\begin{array}{l}\text { Microalbuminuria } \\
30-300 \mathrm{mg} / \mathrm{g}\end{array}$ & $P$-value \\
\hline $\mathrm{N}$ & 123 & 52 & - \\
\hline Sex, m/f (n) & $58 / 65$ & $26 / 26$ & - \\
\hline Age (years) & $41.8 \pm 8.0$ & $44.5 \pm 8.2$ & 0.045 \\
\hline $\mathrm{BMI}\left(\mathrm{kg} / \mathrm{m}^{2}\right)$ & $27.1 \pm 3.4$ & $27.9 \pm 3.4$ & 0.171 \\
\hline WC $(\mathrm{cm})$ & $93.5 \pm 7.1$ & $95.1 \pm 7.2$ & 0.166 \\
\hline $\mathrm{SBP}(\mathrm{mm} \mathrm{Hg})$ & $131.1 \pm 19.0$ & $149.8 \pm 23.4$ & 0.000 \\
\hline $\mathrm{DBP}(\mathrm{mm} \mathrm{Hg})$ & $86.2 \pm 8.7$ & $93.7 \pm 10.9$ & 0.000 \\
\hline $\mathrm{FBG}(\mathrm{mg} / \mathrm{dL})$ & $160.4 \pm 56.1$ & $189.2 \pm 61.4$ & 0.003 \\
\hline TC (mg/dl) & $215.6 \pm 44.3$ & $217.3 \pm 42.9$ & 0.812 \\
\hline $\mathrm{TG}(\mathrm{mg} / \mathrm{dL})$ & $186.9 \pm 55.7$ & $225.0 \pm 114.9$ & 0.004 \\
\hline $\mathrm{HDL}(\mathrm{mg} / \mathrm{dL})$ & $37.1 \pm 5.6$ & $37.6 \pm 6.2$ & 0.659 \\
\hline LDL (mg/dL) & $141.0 \pm 44.1$ & $137.7 \pm 33.7$ & 0.639 \\
\hline $\mathrm{ACR}(\mathrm{mg} / \mathrm{g} \mathrm{Cr})$ & $10.1 \pm 6.1$ & $65.5 \pm 48.5$ & 0.000 \\
\hline Hypertension, n (\%) & $68(55.3)$ & $48(92.3)$ & $>0.01$ \\
\hline Diabetes, n (\%) & $79(64.2)$ & $44(84.6)$ & $>0.05$ \\
\hline
\end{tabular}

$B M I$ body mass index, WC waist circumference, SBP systolic blood pressure, $D B P$ diastolic blood pressure, FBG fasting blood glucose, $T C$ total cholesterol, $T G$ triglyceride, $H D L-C$ high-density lipoprotein cholesterol, $L D L-C$ low-density lipoprotein cholesterol, $A C R$ urinary albumin to creatinine ratio. Data are presented as mean \pm SD. $P$-values are obtained from Independent sample ttest in comparison between the groups. Chi-Square test was applied to determine $p$-values for categorical variables

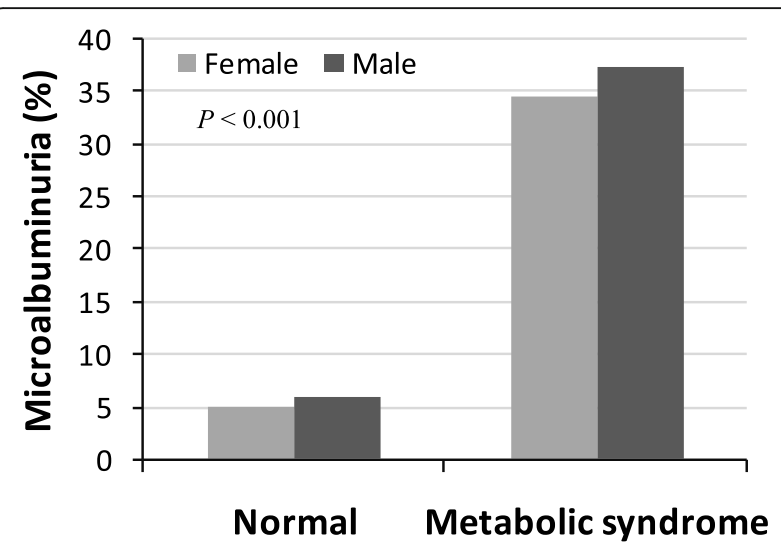

Fig. 1 Prevalence of microalbuminuria by metabolic syndrome. $P<$ 0.001 when compared the prevalence of microalbuminuria between normal and metabolic syndrome groups

the participants $(29.7 \%)$ and much more prevalent in subjects with the MetS (36.0\%) than subjects not having the syndrome $(5.4 \%)$. Of the components of MetS, high FBG and elevated BP were strongly associated with microalbuminuria. The magnitude of the observed association remained even after adjusting for sex, age, BMI and other components of the MetS. Our results indicate that microalbuminuria may be a component of MetS and these findings supporting the results of some previous works [8, 30-34]. To the best of our knowledge, this is the first study that evaluated the relationship between microalbuminuria and MetS among Bangladeshi adults.

The prevalence of microalbuminuria in our study was higher than the studies conducted previously in the Chinese, Japanese and US general population [13, $16,34]$. Where this prevalence was $4.3 \%$ in Chinese [34], $13.7 \%$ in Japanese [13] and $6.4 \%$ in the US population [16]. The differences in the prevalence of microalbuminuria in these populations may be related to the variations in the characteristics of the study subjects, such as age and risk factors of cardiovascular disorders [34]. In the present study, a major portion of the study participants was hypertensive and diabetic and the high prevalence of microalbuminuria in our study supports the evidence that microalbuminuria prevalence is higher in populations with diabetes and hypertension [35-37].

This study finding on the association between microalbuminuria and MetS is in line with the findings of previous studies [13, 16, 34]. The prevalence of microalbuminuria was significantly higher in subjects with the MetS than those without MetS in Chinese (12\% vs $2.9 \%$ ) [34], Japanese (20.8\% vs $12.2 \%$ ) [13] and US adults $(13.7 \%$ vs $4.8 \%)$ [16]. With regard to the relationship of microalbuminuria with the components of MetS, our study results are in line with the 

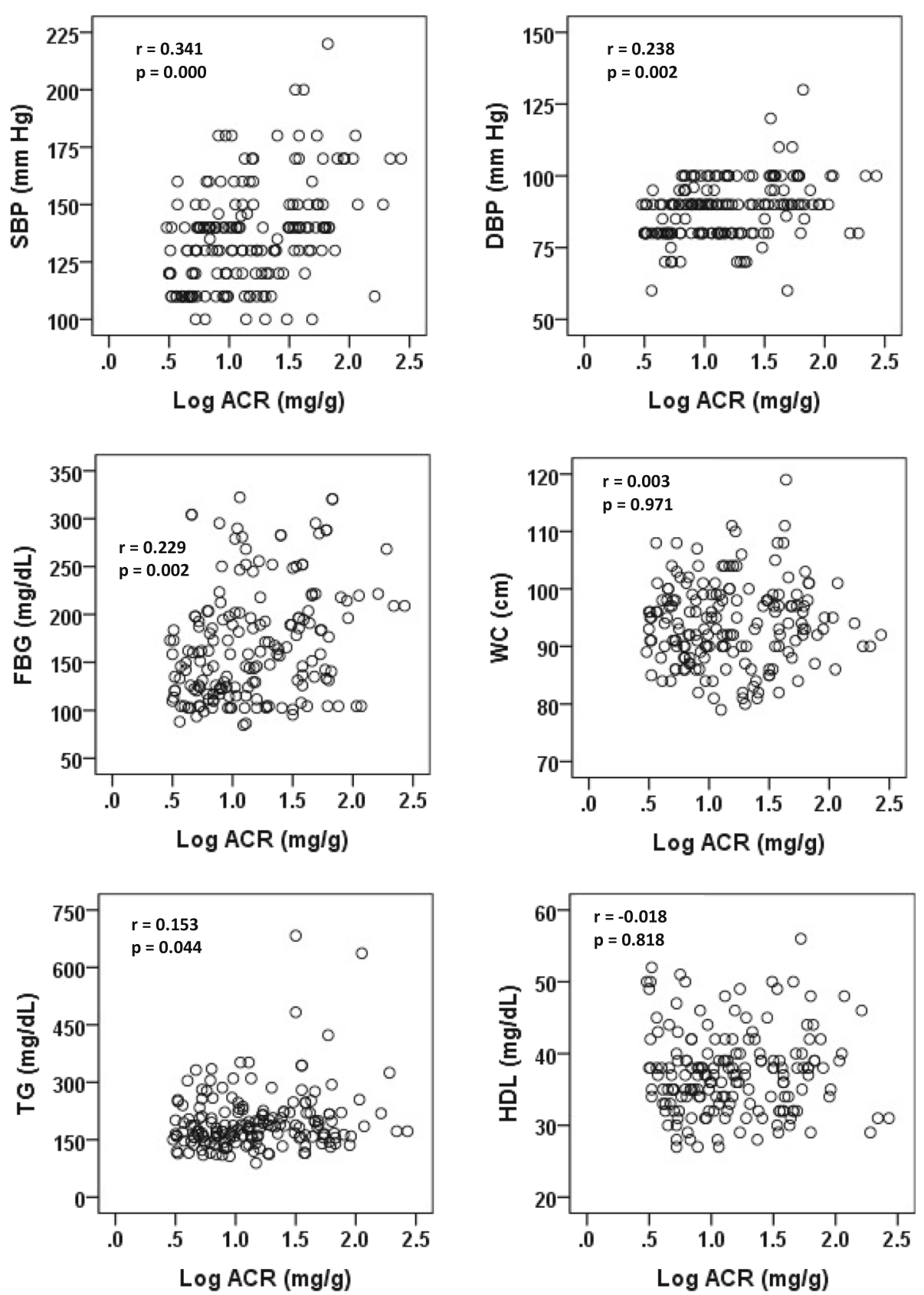

Fig. 2 Association of individual component of metabolic syndrome with ACR (log transformed concentrations)

findings of previous works [13, 14, 16, 34]. For example, in Chinese adults, microalbuminuria was significantly associated with elevated BP and plasma glucose but not with other components of the MetS $[14,34]$. In Japanese adults, a strong relationship was observed for microalbuminuria with elevated BP and hyperglycemia [13]. In the US adults, microalbuminuria was also significantly associated with elevated BP and hyperglycemia but not with the other components of MetS [16]. However, in other studies, microalbuminuria has been found to be associated with all components of MetS [12, 15], and such findings in these studies might be a reason that the components of MetS were not properly adjusted. Nevertheless, in individuals without existing cardiovascular disorders, such as treated hypertension could also be correlated with microalbuminuria [34].

In previous studies, an association was observed between hypertension and microalbuminuria [32, 38]. However, the mechanism for the association of microalbuminuria with hyperglycemia and elevated BP is not clear yet. In clinical studies, microalbuminuria has 
Table 3 Association of microalbuminuria with MetS and its components

\begin{tabular}{lll}
\hline MetS component & Adjusted OR (95\% Cl) & $P$-value \\
\hline Elevated FBG & $2.70(1.58-3.87)$ & 0.001 \\
Large WC & $1.78(0.66-3.84)$ & 0.420 \\
Elevate BP & $3.25(2.30-4.22)$ & 0.001 \\
Elevated TG & $1.96(0.88-3.12)$ & 0.068 \\
Reduced HDL-C & $1.76(0.60-3.56)$ & 0.328 \\
MetS & $4.38(1.88-6.99)$ & 0.001
\end{tabular}

FBG fasting blood glucose, WC waist circumference, BP blood pressure, TG triglyceride, $H D L-C$ high-density lipoprotein cholesterol, MetS metabolic syndrome. Multivariate logistic regression analysis was performed to evaluate the association of microalbuminuria with MetS and its components. The model has been adjusted for sex, age and BMI, and additionally for other components of the metabolic syndrome. $\mathrm{OR}$ odd ratio, $\mathrm{Cl}$ confidence interval

been demonstrated as an indicator of vascular damage and endothelial dysfunction [27]. Imbalanced metabolism of blood lipids and glucose are closely related to the development of MetS [2]. A recent study showed that MetS contributes to arterioles disease [39]. Peripheral circulation is thought to be the main determinant of BP and glucose regulation [34]. The MetS is proposed to be a disease of the periphery, which may be involved in the elevation of BP and hyperglycemia [34]. A study of the Korean population reported that individuals with microalbuminuria had higher blood glucose levels than individuals without microalbuminuria [40].

There are some limitations to this study. First, the cross-sectional nature of the data may preclude the causality between microalbuminuria and MetS being assumed. Second, the sample size was relatively small. Third, ACR was measured once in the collected morning urine. However, the high diagnostic precision of a spot urine collection could reduce the doubt related to inter-day variations in the rate of albumin excretion. Measurement of ACR in spot urine offers proper estimation in the epidemiologic surveys and has been used in many other previous studies [16, 30, 32, 41].

\section{Conclusions}

This study reports the prevalence of microalbuminuria in Bangladeshi adults and this prevalence is more frequent in subjects with MetS, mainly attributable to high blood glucose and elevated BP. Moreover, the present study indicates a strong association between microalbuminuria and MetS in Bangladeshi adults. Further longitudinal studies are required to explore the relationship between microalbuminuria and MetS in diabetic and hypertensive individuals.

\section{Abbreviations}

MetS: Metabolic syndrome; BMI: Body mass index; TG: Triglycerides; TC: Total cholesterol; LDL: Low-density lipoprotein; HDL: High-density lipoprotein; WHO: Word Health Organization

\section{Acknowledgments}

The authors wish to thank the healthcare technicians for their assistance in sampling and data collection. The authors are grateful to all participants for their participation in this study.

\section{Authors' contributions}

MMS played a significant role in sample collection and laboratory analysis. MNR and RH played a role in conception and design of the study. FAT and SM helped in data collection and contributed to the result section. NA played a major role in the conception, analyzing and interpreting data and wrote the manuscript. All authors read the manuscript and approved the final version.

\section{Funding}

This study did not receive any external funding.

\section{Availability of data and materials}

The datasets used and analyzed during the present study are available from the corresponding author on reasonable request.

\section{Ethics approval and consent to participate}

This study was approved by the institutional Ethics Committee of Sir Salimullah Medical College and Hospital, Dhaka, Bangladesh. All participants were informed about the study aims and they provided written consent before inclusion in the study.

\section{Consent for publication}

Not applicable.

\section{Competing interests}

The authors have no competing interests to declare.

\section{Author details}

${ }^{1}$ Department of Biochemistry, Netrokona Medical College, Netrokona, Bangladesh. ${ }^{2}$ Department of Biochemistry, Sir Salimullah Medical College, Dhaka, Bangladesh. ${ }^{3}$ Department of Biochemistry, Ad-Din Women's Medical College, Dhaka, Bangladesh. ${ }^{4}$ Department of Biochemistry, Gonoshasthaya Samaj Vittik Medical College, Savar, Dhaka 1344, Bangladesh. ${ }^{5}$ Department of Biochemistry and Molecular Biology, Shahjalal University of Science and Technology, Sylhet 3114, Bangladesh.

Received: 25 March 2020 Accepted: 1 October 2020

Published online: 07 October 2020

\section{References}

1. Gerstein HC, Mann JF, Yi Q, Zinman B, Dinneen SF, Hoogwerf B, et al. Albuminuria and risk of cardiovascular events, death, and heart failure in diabetic and nondiabetic individuals. JAMA. 2001;286:421-6.

2. Lambers Heerspink HJ, Brinkman JW, Bakker SJL, Gansevoort RT, de Zeeuw D. Update on microalbuminuria as a biomarker in renal and cardiovascular disease. Curr Opin Nephrol Hypertens. 2006;15:631-6.

3. Ochodnicky P, Henning RH, van Dokkum RPE, de Zeeuw D. Microalbuminuria and endothelial dysfunction: emerging targets for primary prevention of end-organ damage. J Cardiovasc Pharmacol. 2006;47(Suppl 2): S151-62 discussion S172-176.

4. Alberti KG, Zimmet PZ. Definition, diagnosis and classification of diabetes mellitus and its complications. Part 1: diagnosis and classification of diabetes mellitus provisional report of a WHO consultation. Diabet Med J $\mathrm{Br}$ Diabet Assoc. 1998;15:539-53.

5. Bianchi S, Bigazzi R, Campese VM. Microalbuminuria in essential hypertension: significance, pathophysiology, and therapeutic implications. Am J Kidney Dis Off J Natl Kidney Found. 1999;34:973-95.

6. Scaglione R, Ganguzza A, Corrao S, Parrinello G, Merlino G, Dichiara MA, et al. Central obesity and hypertension: pathophysiologic role of renal haemodynamics and function. Int J Obes Relat Metab Disord J Int Assoc Study Obes. 1995;19:403-9. 
7. Grundy SM. Metabolic syndrome: a multiplex cardiovascular risk factor. J Clin Endocrinol Metab. 2007;92:399-404.

8. Isomaa B, Almgren P, Tuomi T, Forsén B, Lahti K, Nissén M, et al. Cardiovascular morbidity and mortality associated with the metabolic syndrome. Diabetes Care. 2001;24:683-9.

9. Laaksonen DE, Lakka H-M, Niskanen LK, Kaplan GA, Salonen JT, Lakka TA Metabolic syndrome and development of diabetes mellitus: application and validation of recently suggested definitions of the metabolic syndrome in a prospective cohort study. Am J Epidemiol. 2002;156:1070-7.

10. Grundy SM, Cleeman Jl, Daniels SR, Donato KA, Eckel RH, Franklin BA, et al. Diagnosis and management of the metabolic syndrome: an American Heart Association/National Heart, Lung, and Blood Institute scientific statement. Circulation. 2005;112:2735-52.

11. National Cholesterol Education Program. Third report of the National Cholesterol Education Program (NCEP) expert panel on detection, evaluation, and treatment of high blood cholesterol in adults (adult treatment panel III) final report. Circulation. 2002:106:3143-421.

12. Chen $B$, Yang $D, C$ Chen $Y, X u W, Y e B, N i Z$. The prevalence of microalbuminuria and its relationships with the components of metabolic syndrome in the general population of China. Clin Chim Acta Int J Clin Chem. 2010;411:705-9.

13. Hao Z, Konta T, Takasaki S, Abiko H, Ishikawa M, Takahashi T, et al. The association between microalbuminuria and metabolic syndrome in the general population in Japan: the Takahata study. Intern Med Tokyo Jpn. 2007:46:341-6

14. Li Q, Jia W, Lu J, Chen L, Wu Y, Jiang $S$, et al. Relationship between the prevalence of microalbuminuria and components of metabolic syndrome in Shanghai. Zhonghua Liu Xing Bing Xue Za Zhi Zhonghua Liuxingbingxue Zazhi. 2004;25:65-8.

15. Lin C-C, Liu C-S, Li T-C, Chen C-C, Li C-I, Lin W-Y. Microalbuminuria and the metabolic syndrome and its components in the Chinese population. Eur J Clin Investig. 2007:37:783-90.

16. Palaniappan L, Carnethon M, Fortmann SP. Association between microalbuminuria and the metabolic syndrome: NHANES III. Am J Hypertens. 2003;16(11 Pt 1):952-8.

17. Chen J, Muntner P, Hamm LL, Jones DW, Batuman V, Fonseca V, et al. The metabolic syndrome and chronic kidney disease in U.S. adults. Ann Intern Med. 2004;140:167-74.

18. Chowdhury MZI, Anik AM, Farhana Z, Bristi PD, Abu Al Mamun BM, Uddin $\mathrm{MJ}$, et al. Prevalence of metabolic syndrome in Bangladesh: a systematic review and meta-analysis of the studies. BMC Public Health. 2018;18:308.

19. Ali N, Miah R, Hasan M, Barman Z, Mou AD, Hafsa JM, et al. Association between serum uric acid and metabolic syndrome: a cross-sectional study in Bangladeshi adults. Sci Rep. 2020;10:7841.

20. Islam S, Rahman S, Haque T, Sumon AH, Ahmed AM, Ali N. Prevalence of elevated liver enzymes and its association with type 2 diabetes: a crosssectional study in Bangladeshi adults. Endocrinol Diabetes Metab. 2020. https://doi.org/10.1002/edm2.116.

21. Ali N, Rahman S, Islam S, Haque T, Molla NH, Sumon AH, et al. The relationship between serum uric acid and lipid profile in Bangladeshi adults. BMC Cardiovasc Disord. 2019;19:42.

22. Ali N, Perveen R, Rahman S, Mahmood S, Rahman S, Islam S, et al. Prevalence of hyperuricemia and the relationship between serum uric acid and obesity: a study on Bangladeshi adults. PLoS One. 2018;13:e0206850.

23. Haque T, Rahman S, Islam S, Molla NH, Ali N. Assessment of the relationship between serum uric acid and glucose levels in healthy, prediabetic and diabetic individuals. Diabetol Metab Syndr. 2019;11:49.

24. Rahman S, Islam S, Haque T, Kathak RR, Ali N. Association between serum liver enzymes and hypertension: a cross-sectional study in Bangladeshi adults. BMC Cardiovasc Disord. 2020;20:128.

25. Ali N, Mahmood S, Islam F, Rahman S, Haque T, Islam S, et al. Relationship between serum uric acid and hypertension: a cross-sectional study in Bangladeshi adults. Sci Rep. 2019;9:9061.

26. Ali N, Mahmood S, Manirujjaman M, Perveen R, Al Nahid A, Ahmed S, et al. Hypertension prevalence and influence of basal metabolic rate on blood pressure among adult students in Bangladesh. BMC Public Health. 2017;18: 58.

27. NCEP. Executive summary of the third report of the National Cholesterol Education Program (NCEP) expert panel on detection, evaluation, and treatment of high blood cholesterol in adults (adult treatment panel III). JAMA. 2001;285:2486-97.
28. Chobanian AV, Bakris GL, Black HR, Cushman WC, Green LA, Izzo JL, et al. Seventh report of the Joint National Committee on Prevention, Detection, Evaluation, and Treatment of High Blood Pressure. Hypertens Dallas Tex 1979. 2003:42:1206-52.

29. American Diabetes Association. Classification and Diagnosis of Diabetes: Standards of Medical Care in Diabetes-2018. Diabetes Care. 2018;41(Suppl 1):S13-27.

30. Hoehner CM, Greenlund KJ, Rith-Najarian S, Casper ML, McClellan WM Association of the insulin resistance syndrome and microalbuminuria among nondiabetic native Americans. The inter-tribal heart project. J Am Soc Nephrol JASN. 2002;13:1626-34.

31. Li X-H, Lin H-Y, Wang S-H, Guan L-Y, Wang Y-B. Association of Microalbuminuria with metabolic syndrome among aged population. Biomed Res Int. 2016;2016:1-7.

32. Liese AD, Hense HW, Döring A, Stieber J, Keil U. Microalbuminuria, central adiposity and hypertension in the non-diabetic urban population of the MONICA Augsburg survey 1994/95. J Hum Hypertens. 2001;15:799-804.

33. Mykkänen L, Zaccaro DJ, Wagenknecht LE, Robbins DC, Gabriel M, Haffner SM. Microalbuminuria is associated with insulin resistance in nondiabetic subjects: the insulin resistance atherosclerosis study. Diabetes. 1998;47:793800.

34. Sheng C-S, Hu B-C, Fan W-X, Zou J, Li Y, Wang J-G. Microalbuminuria in relation to the metabolic syndrome and its components in a Chinese population. Diabetol Metab Syndr. 2011;3:6.

35. Gerstein HC, Mann JF, Pogue J, Dinneen SF, Hallé JP, Hoogwerf B, et al. Prevalence and determinants of microalbuminuria in high-risk diabetic and nondiabetic patients in the Heart Outcomes Prevention Evaluation Study. The HOPE Study Investigators. Diabetes Care. 2000;23(Suppl 2):B35-9.

36. Lindeman RD, Romero L, Liang HC, Hundley R, Baumgartner R, Koehler K, et al. Prevalence of proteinuria/microalbuminuria in an elderly urban, biethnic community. Geriatr Nephrol Urol. 1998:8:123-30.

37. Wrone EM, Carnethon MR, Palaniappan L, Fortmann SP. Third National Health and nutrition examination survey. Association of dietary protein intake and microalbuminuria in healthy adults: third National Health and nutrition examination survey. Am J Kidney Dis Off J Natl Kidney Found. 2003:41:580-7.

38. Srinivasan $S R$, Myers $L$, Berenson GS. Risk variables of insulin resistance syndrome in African-American and Caucasian young adults with microalbuminuria: the Bogalusa heart study. Am J Hypertens. 2000;13:12749.

39. Levy Bl, Schiffrin EL, Mourad J-J, Agostini D, Vicaut E, Safar ME, et al. Impaired tissue perfusion: a pathology common to hypertension, obesity, and diabetes mellitus. Circulation. 2008;118:968-76.

40. Kim Yl, Kim C-H, Choi CS, Chung YE, Lee MS, Lee SI, et al. Microalbuminuria is associated with the insulin resistance syndrome independent of hypertension and type 2 diabetes in the Korean population. Diabetes Res Clin Pract. 2001;52:145-52.

41. Jager A, Kostense PJ, Ruhé HG, Heine RJ, Nijpels G, Dekker JM, et al. Microalbuminuria and peripheral arterial disease are independent predictors of cardiovascular and all-cause mortality, especially among hypertensive subjects: five-year follow-up of the Hoorn study. Arterioscler Thromb Vasc Biol. 1999;19:617-24.

\section{Publisher's Note}

Springer Nature remains neutral with regard to jurisdictional claims in published maps and institutional affiliations.

Ready to submit your research? Choose BMC and benefit from:

- fast, convenient online submission

- thorough peer review by experienced researchers in your field

- rapid publication on acceptance

- support for research data, including large and complex data types

- gold Open Access which fosters wider collaboration and increased citations

- maximum visibility for your research: over $100 \mathrm{M}$ website views per year

At $\mathrm{BMC}$, research is always in progress.

Learn more biomedcentral.com/submission 